\title{
Actuation Of Changeable Optical Properties By A Construction Node Temperature - An Example Of PCM-Window
}

\author{
Anna Wieprzkowicz ${ }^{1}$, Dariusz Heim ${ }^{1}$ \\ ${ }^{1}$ Lodz University of Technology, Lodz, Poland
}

\begin{abstract}
The paper presents the results of numerical analysis of complex, triple glazed window with PCM layer. The optical properties substitution due to change of phase is executed by refined control algorithms for windows. The idea of the control/actuator algorithm and its implementation in ESP-r software was described. Using the proposed method the simulations were executed for two extreme summer months under moderate climatic conditions. Five different paraffin waxes were analysed as a PCM filling and compared with traditional triple glazed window. The results were analyzed in terms of energy for cooling, energy for lighting, visual discomfort, glare effect and thermal discomfort. It was concluded that there is no one optimal type of PCM, and the best solution is to divide the glazing into sections filled with PCM with different melting temperatures.
\end{abstract}

\section{Introduction}

Requirements for newly design buildings and thermal modernization activities in central Europe focus mainly on the decrease of thermal transmittance and lowering the heating energy demand while problem of thermal mass seem to be neglected. As a result today constructions become highly insulated and effective during the winter season but also characterized by lower thermal inertia and less efficient in summer. Since the thermal inertia describes the building dynamic response for a thermal wave, its decrease can lead to such problems like overheating, not only during the summer days. As rising cooling energy demand becomes a challenge even under cold climate conditions it creates the need for a new, effective approach to be developed.

It was widely recognized that overheating during warm summer days is caused mainly by the excessive solar heat gains through transparent parts of the building envelope. Thus, the most effective way to limit the cooling energy needs is modification of the transparent construction or glazing properties as such. Thermal performance of the glazing can be improved by the increase of its thermal resistance or by the increase of its thermal mass (Liu et al., 2017). As far as lowering of the cooling energy demand is under consideration, the second one approach seem to be more suitable.

One of the ideas to increase thermal mass of the glazing component is application of the phase change material (PCM). Such an approach is under the investigation since almost twenty years (Ismail and Henríquez, 1997) but there are still many aspects that requires more research activities (Silva, Vicente and Rodrigues, 2016). Most of the research results proving the efficiency of the PCMglazing comes from the experimental research conducted in warm climatic conditions (Goia, Perino and Serra, 2014; Liu et al., 2018). Thermal performance of the windows was also widely investigated numerically in terms of different thermophysical properties ( $\mathrm{Li}$ et al., 2016; Zhong et al., 2015), layer thicknesses and melting temperatures of PCM (Liu et al., 2017) and optical properties (Li, Ma, et al., 2016). Nevertheless most of the presented approaches consider only the thermal behaviour of the glazing, not considering the fenestration as a part of the whole building defined as an one energy system. As underlined by Goia (Goia et al., 2015) most of the research activities concerning the problem of PCMglazing is experimental because simulation of such system is very complex and requires collection of the input data about the system. In order to conduct robust numerical analysis of the PCM-window system it is important to precisely determine not only thermal but also optical properties of such fenestration, in solid state (Goia et al., 2015) but also for liquid and mushy phase (Heim et al., 2018).

The first challenge that was faced and described in the paper was adjustment of the calculation procedure, implemented in commonly used whole-building simulation software - ESP-r, in such a way that change of material phase will also trigger the change of optical properties of the material. Such an facilitation can be utilized for simulation of any system, under variable boundary conditions and can contribute to better understanding of the thermo-optical performance of PCM-glazing systems, including the influence of all energy flows in the building. Furthermore, modified calculation procedure implemented in ESP-r was used to investigate the performance of triple-glazed window enhanced by PCM in terms of energy demand for cooling and artificial lighting but also thermal and visual comfort aspects were investigated.

\section{Method}

Due to the fact that optical properties of the PCM extremely changes during the phase transition it is crucial to include this effect in the model and further in the simulation analysis. Based on the previously conducted experimental study it was observed that PCM in solid 
state can have even 10 times lower visible transmittance than in liquid state, for the layer thickness of $16 \mathrm{~mm}$. Such phenomena have its consequences for both thermal and visual performance analysis. It can be stated that properly designed window enhanced by the PCM layer works as a window equipped with the blinds controlled by the external weather conditions.

The one of the computational environments allowing whole building simulation including most advanced optical properties definition is ESP-r software. Besides the extended possibilities to define the optical properties in accordance to the angle of incidence, values of the total reflectance, absorption, transmission as well as visible transmittance can be controlled and switched under specified conditions. The existing ESPsim control procedure implemented in ESP-r software is used to define the actuator for window blinds control (Strachan, 1990). In the existing approach optical properties can have scheduled controls which allow an alternative optical property to be used based on the following sensed parameters:

a) time - alternative optics are used during a specific period of the day,

b) total radiation on the outside face of a surface in the zone - specified radiation level $\left(\mathrm{W} / \mathrm{m}^{2}\right)$ above which the alternate optical properties will be used,

c) ambient temperature - specified external temperature above which the alternative optical properties will be used,

d) zone air temperature - specified internal temperature above which the alternative optical properties will be used,

e) illuminance - specified lux level above which the alternative optical properties will be used (two alternative lux calculation approaches are available).

For all listed properties substitution option there is possibility to define up to 8 control periods in a day but all days within the simulation are treated the same. Moreover, the alternative optics must correspond to the same number of layers as the initial set.

The challenge that was faced and described in the paper was extension of the properties substitution procedure to facilitate it in order to simulate PCM-window. As stated before, such PCM transition results in similar thermal effect as blind operation, but the control procedure is different. In case of blinds, the closing and opening is adjusted to the indoor comfort requirements while modelling of the PCM-window should be rather treated in a different manner where changes of optical properties are triggered by the temperature of the material (Liu et al., 2018). In that case the change of optical properties should be determined by the process of phase transition. In solid state the transmittance is much lower and transmitted radiation is diffused. In liquid state the material become transparent. Since phase transition and thus optical properties change occur in the specified, phase transition temperature - characteristic for each PCM, it was stated that optical properties substitution should be triggered by the temperature of the material. In ESP-r software each building component layer is defined by three nodes - on both external and internal surfaces of the layer and in the middle. It was stated that switch of the optical properties should be triggered by the temperature calculated for the central node of the PCM layer, as the special material properties and latent heat accumulation are also assigned to that node. It means, that in specified temperature, when phase transition occurs not only additional effect of latent heat accumulation will be considered but also change of optical properties will influence the thermal calculations in the next simulation time-step.

In the contrary to the latent heat accumulation model, for which it was possible to assign the phase transition temperature range, optical properties switch modelled in ESP-r occur in specified temperature. The additional function of properties substitution was added in the source code of the software (solar.F file) and tested. The properties of PCM window were previously determined and defined in ESP-r format for both states (Heim, et al. 2018) and the enhanced model was used for the simulation supporting the design of new hybrid translucent component.

\section{Case study}

The main goal of the simulation study was investigation and assessment of the PCM-window performance and design of its thermal properties, by selection of the most effective PCM transition temperature. In order to meet that goal simulation study was performed, using ESP-r computational environment. The procedure of the optical properties substitution was modified and facilitated to allow change of optical properties due to temperature change of the node inside the window cavity. Two office rooms with the PCM-window facing east and west were modelled in such a way to reflect the future experimental facility. Special attention was put on the proper definition of the optical properties of the window, which were previously determined experimentally. Triple glazed window with PCM filled external cavity was analysed for the period of two extreme summer months (July and August) under moderate climate conditions. Three most important climate parameters such as temperature, diffuse and direct solar radiation used in simulation were presented in Figure 1 (data of Typical Meteorological Year was used).

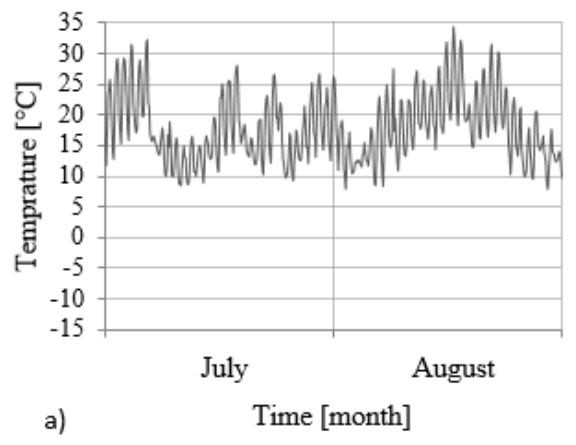




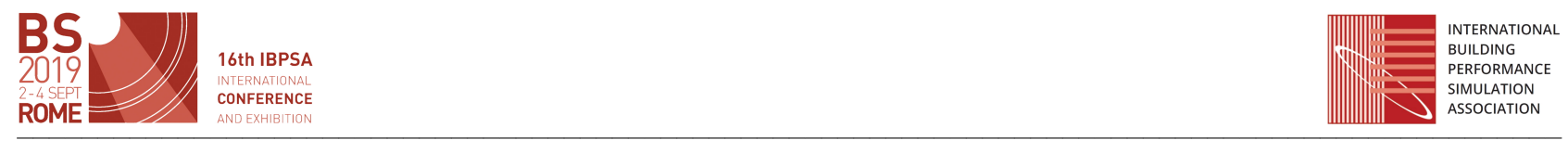
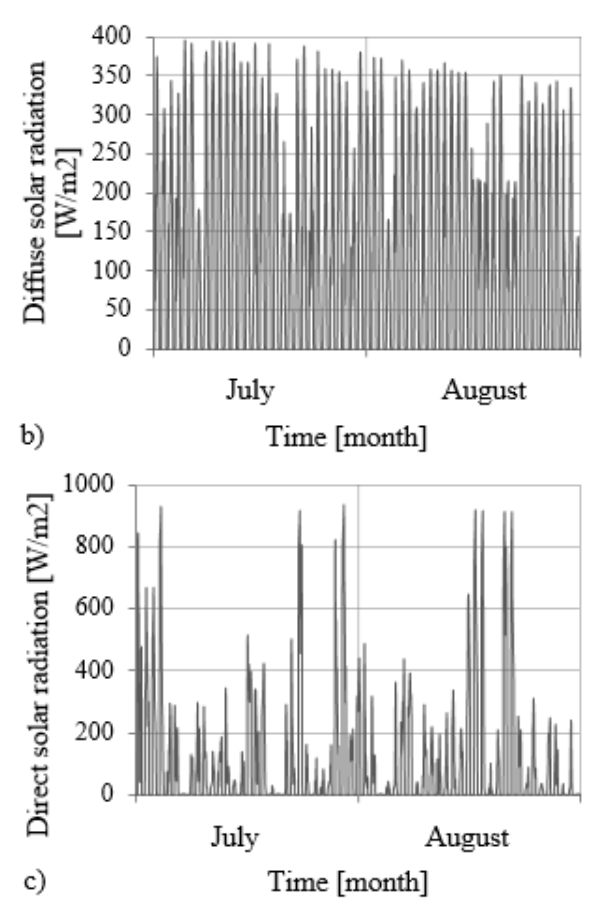

Figure 1.Wether data used in calculation.

Results were obtained for five cases of different PCM transition temperatures and compared with reference case of the standard window (with two cavities filled with gaseous medium). The results were analysed in terms of energy for cooling, energy for lighting, visual discomfort, glare effect and thermal discomfort. Conclusions from the study were needed for further experimental research works.

\section{Geometry and boundary conditions}

Simulation analysis was performed using ESP-r computational environment. It was assumed that performance of the PCM-window will be tested for the same assumptions as future experimental research. Thus, one office room was modelled, with the dimensions of $2.6 \mathrm{~m} \times 2.4 \mathrm{~m} \times 4.4 \mathrm{~m}(\mathrm{~h} \times \mathrm{w} \times 1)$ with the centrally positioned square window with surface of $1 \mathrm{~m}^{2}$. Modelled office is surrounded by other rooms, thus it was assumed that only one wall (the one with window) will be treated as external one, while for others adiabatic boundary conditions were set (as well as for floor and ceiling). Two office rooms were analysed - with east and west directed window (mirror reflected geometry).

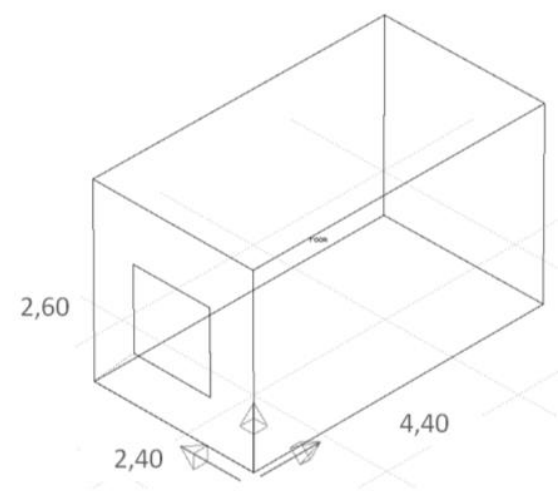

Figure 2. Geometry of the analysed case.

\section{Ventilation and internal heat gains}

Since all settings were assumed to reflect future experimental set-up, ventilation modes and internal heat gains were also considered as in a real scale experiment. Firstly, all assumption were differentiated for two rooms due to the fact of differentiated occupancy. East oriented office was designed to be occupied by two persons while in west oriented office only one person will be working. Such assumption influenced both the level of ventilation air exchange and internal heat gains. Fresh air is supplied by under-floor decentralized ventilation unit which gives possibility to adjust both the intensity and time of air supply. It was assumed that both offices will be occupied between 8 and 16 hour and during that time ventilation rate will be adjusted to the hygienic needs of the occupants. For west oriented office the ventilation rate was set at $20 \mathrm{~m}^{3} / \mathrm{h}$ while for the second room was doubled due to twice increased occupancy. Moreover, for both offices increased, intensive ventilation was set between 6 and 7 hour, at the level of $90 \mathrm{~m}^{3} / \mathrm{h}$ in order to assure fresh and not overheated air before the working day starts. During the rest of the time of the day the lowest set up was assumed at the level of $15 \mathrm{~m}^{3} / \mathrm{h}$ (Table 1).

Table 1: Ventilation and heat gains set assumed in the analysis.

\begin{tabular}{|c|c|c|c|c|}
\hline \multirow{2}{*}{ Time } & \multicolumn{2}{|c|}{$\begin{array}{c}\text { East } \\
\text { 2-person office }\end{array}$} & \multicolumn{2}{c|}{$\begin{array}{c}\text { West } \\
\text { 1-person office }\end{array}$} \\
\cline { 2 - 5 } & $\begin{array}{c}\text { Ventilation } \\
{[\mathrm{m} 3 / \mathrm{h}]}\end{array}$ & $\begin{array}{c}\text { Heat } \\
\text { gains } \\
{[\mathrm{W}]}\end{array}$ & $\begin{array}{c}\text { Ventilation } \\
{[\mathrm{m} 3 / \mathrm{h}]}\end{array}$ & $\begin{array}{c}\text { Heat } \\
\text { gains } \\
{[\mathrm{W}]}\end{array}$ \\
\hline $0-6$ & 15 & 0 & 15 & 0 \\
\hline $6-7$ & 90 & 0 & 90 & 0 \\
\hline $7-8$ & 15 & 0 & 15 & 0 \\
\hline $8-16$ & 40 & $\begin{array}{c}150- \\
\text { people } \\
220- \\
\text { equip. }\end{array}$ & 20 & $\begin{array}{c}75- \\
\text { people } \\
110- \\
\text { equip. }\end{array}$ \\
\hline $16-24$ & 15 & 0 & 15 & 0 \\
\hline
\end{tabular}

As stated before, two offices differs in number of occupants, thus internal heat gains were also doubled for east oriented room when compared to the second one. It was assumed that occupancy of one person will bring $75 \mathrm{~W}$ of heat gains and equipment used by this person additional $110 \mathrm{~W}$.

\section{Window construction and materials}

It was assumed that triple glazed window will be analysed. Thickness of the glass was $4 \mathrm{~mm}$ and both cavities has thickness of $16 \mathrm{~mm}$ - external one filled with PCM and internal filled with gaseous medium.

Latent heat accumulation was modelled using effective heat capacity method and cavity filled with PCM was modelled as one layer. Five paraffin waxes were considered in the analysis, varied in terms of phase transition temperatures and latent heat capacity. All considered PCMs have the same specific heat and 
conductivity, which were assumed the same for liquid and solid state (Table 2).

Based on the manufacturer data for each analysed material the apparent heat capacity function was calculated in such a way to obtain the best fit between model and real material performance.

Table 2: Thermal properties of the analysed PCMs

\begin{tabular}{|c|c|c|c|c|}
\hline \multirow{2}{*}{ PCM } & $\begin{array}{c}\text { Phase } \\
\text { change } \\
\text { temp. } \\
\text { range } \\
{\left[{ }^{\circ} \mathbf{C}\right]}\end{array}$ & $\begin{array}{c}\mathbf{L} \\
{[\mathbf{k J} / \mathbf{k g}]}\end{array}$ & $\begin{array}{c}\boldsymbol{\lambda} \\
{[\mathbf{W} / \mathbf{m K}]}\end{array}$ & $\begin{array}{c}\mathbf{C p} \\
{[\mathbf{k J} / \mathbf{k g K}]}\end{array}$ \\
\hline RT18HC & $17-19$ & 260 & & \\
\cline { 1 - 2 } RT22HC & $19-24$ & 190 & \multirow{2}{*}{0.2} & \multirow{2}{*}{2000} \\
\cline { 1 - 2 } RT25HC & $18-26$ & 230 & & \\
\hline RT28HC & $26-29$ & 250 & & \\
\hline RT31 & $27-34$ & 166 & & \\
\hline
\end{tabular}

\section{Optical properties}

Change of the optical properties during the phase transition was modelled according to the method described above. Based on the results of the measurements the data sets were calculated and implemented in ESP-r format. For both liquid and solid state of PCM as well as for reference window all necessary data was introduced as showed in Figure 3. For each window construction and for each of its layers the absorbance was calculated in accordance to the angle of incidence (blue lines). Moreover, reflectance (blue line) and direct transmission (red line) were also defined as a function of the angle of incidence. Additionally, the visible transmittance was measured for each construction and was equal 0.71 for reference window, 0.64 for window with liquid PCM and 0.06 for window with solid PCM.

It was assumed that optical properties will be changed according to the value of the temperature calculated for the central node of the PCM layer (Figure 4). For each paraffin the switch temperature was set at its melting temperature peak (Table 3). It means that below that temperature thermal performance was calculated as for window with PCM in solid state and when central PCM node reached peak melting temperature optical properties were substituted for those designated for window with PCM in liquid state. Furthermore, when temperature calculated in subsequent time steps of calculation exceeded this assumed switch temperature optical properties were still kept as for window with liquid paraffin until the temperature dropped down again below this switch temperature. Such an approach allowed to include in the analysis not only latent heat accumulation in PCM layer, but also effect of the significant change in material transparency during the phase transition. It affected not only thermal performance of the window but also visual and comfort parameters in the adjacent office room.

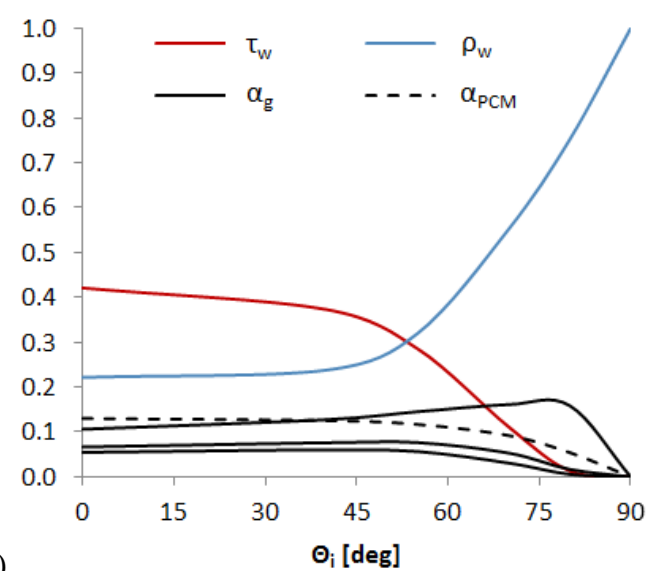

a)

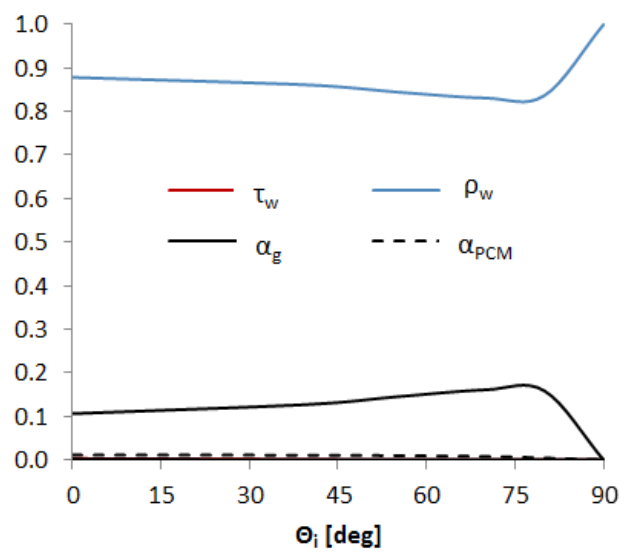

b)

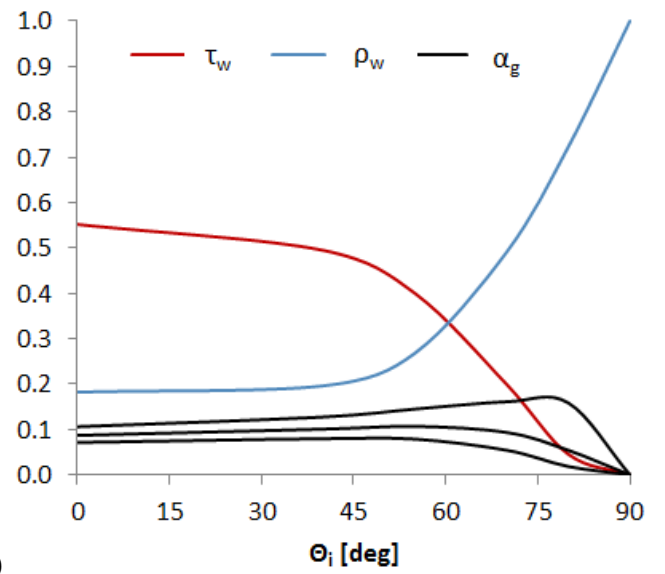

Figure 3. Optical properties of the a) window with PCM in liquid state, $b$ ) window with PCM in solid state,

c) reference window.

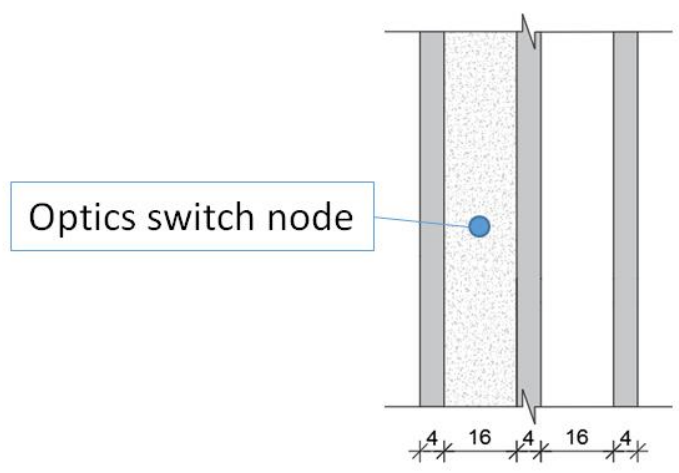

Figure 4. Location of the optical properties switch node. 
Table 3. Temperatures of the optical properties switch.

\begin{tabular}{|c|c|}
\hline PCM type & $\begin{array}{c}\text { Temperature of the optical } \\
\text { properties switch }\left[{ }^{\circ} \mathbf{C}\right]\end{array}$ \\
\hline RT18HC & 18 \\
\hline RT22HC & 22 \\
\hline RT25HC & 25 \\
\hline RT28HC & 28 \\
\hline RT31 & 31 \\
\hline
\end{tabular}

\section{Results}

\section{Cooling energy}

Since it was stated that PCM-window should be designed for the extreme summer months, the first analysed parameter was energy demand for cooling, calculated for the central Europe climatic conditions (city of Lodz, Poland), for July and August. Analysis was performed for two mirror-reflected office rooms described above oriented east and west. Energy for cooling was calculated assuming cooling set-point at $26^{\circ} \mathrm{C}$. Results obtained for window filled with five different paraffin were compared with the energy demand calculated for traditional window - reference case.

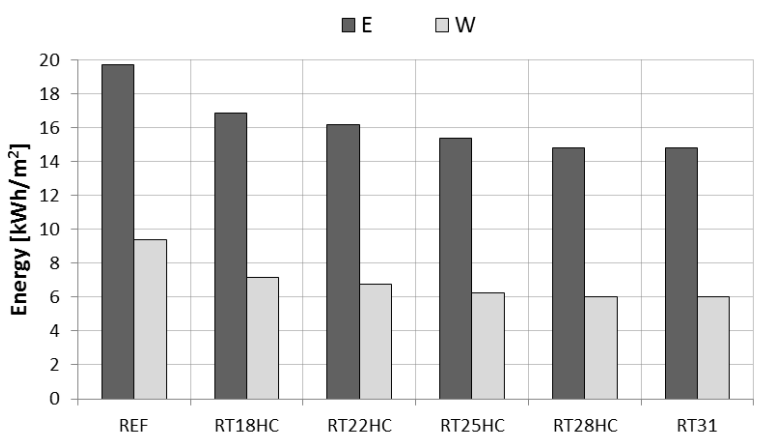

Figure 5. Cooling energy demand for east and west oriented office calculated for two extreme summer months for the location of Lodz.

Based on the results presented in Figure 5 it can be observed that for both offices application of the PCM contributed to the decrease of cooling energy demand. The higher melting temperature of the material the higher cooling energy savings were obtained (Table 4). Such tendency can be justified by two phenomena:

- $\quad$ Higher melting temperature is more suitable for climatic conditions characteristic for extreme summer months - high solar radiation and ambient temperature which results in more effective phase transition process and increased latent heat accumulation,

- $\quad$ The higher melting temperature the longer time material remains in solid state which results in longer time when PCM works as blinds, reducing heat gains and temperature rise inside the adjacent room.

Table 4. Comparison between energy demand obtained for reference and PCM-window.

\begin{tabular}{|c|c|c|c|c|c|}
\hline \multirow{2}{*}{$\begin{array}{c}\text { Orient } \\
\text { ation }\end{array}$} & \multicolumn{5}{|c|}{$\begin{array}{c}\text { Decrease of cooling energy demand in } \\
\text { accordance to the reference case [\%] }\end{array}$} \\
\cline { 2 - 6 } & RT18HC & RT22HC & RT25HC & RT28HC & RT31 \\
\hline E & 14.7 & 18.0 & 22.0 & 24.9 & 25.0 \\
\hline W & 11.2 & 13.2 & 15.8 & 17.1 & 17.1 \\
\hline
\end{tabular}

\section{Energy for artificial lighting}

Considering the fact that transition temperature of PCM and its transparency influence not only cooling energy demand but also visual conditions inside the adjacent room, the second analysed parameter was energy needed for artificial lighting.

Energy demand for artificial lighting was calculated based on the number of hours when PCM is in liquid and solid state, which were designated accordingly to the current temperature of PCM node. Based on the previously conducted analysis and calculated values of UDI parameter it was assumed that reference window and window with liquid PCM will provide sufficient daylight during $70 \%$ time of the day (Heim et al., 2013), while in case of window with PCM in solid state artificial lighting will be needed during the all day. Power of the lighting was assumed as installed in the office room where full scale experiment will be conducted at the level of $90 \mathrm{~W}$. It means that energy for artificial lighting was calculated using formula:

$$
E_{l}=\frac{\left(0.3 H_{l}+H_{S}\right) 90}{1000 \cdot A}\left[\frac{k W h}{m^{2}}\right]
$$

where:

$H_{l}$ - number of hours when PCM is in liquid state (for reference case whole analysed period of time); $H_{s}$ - number of hours when PCM is in solid state; $A$ - area of the office room.

Due to the adopted assumptions each application of PCM in window should result in the increased need for energy for artificial lighting. Based on the results presented in Figure 6 it can be observed that, in contrary to the values obtained for energy for cooling, energy for artificial lighting increases with the increase of the melting temperature of the PCM. It can be justified by the fact that material with higher melting temperature needs bigger input of the heat from the outside to melt, so stays in solid state for a longer time.

Comparison between values obtained for both offices showed that east oriented façade is more exposed for high temperatures and solar radiation (more than twice higher cooling energy demand than for western façade) so melting process occurs earlier and less energy for artificial lighting is needed.

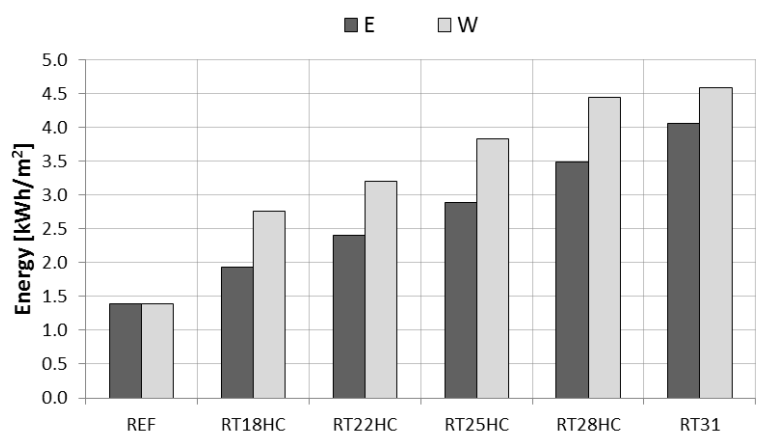

Figure 6. Energy demand for artificial lighting for east and west oriented office. 


\section{Thermal comfort}

Besides the energy aspects of the PCM application in the window cavity, it has also great impact on the thermal conditions and thermal comfort of the occupants in the adjacent office room. In order to access thermal comfort quantitatively and qualitatively degree-hours of the overheating were calculated and compared (Figure 7) using formula:

$$
D H O=\sum_{i=1}^{n}\left(T_{i}-26\right) \cdot t[K \cdot h]
$$

where:

$T_{i}$ - instantaneous value of the room temperature $\left[{ }^{\circ} \mathrm{C}\right]$; $t$ - length of the time step of calculation [h]; $i$ - subsequent number of the time step [-]; $n$-number of the time steps of analysis [-].

Analysis of the thermal comfort was performed assuming no cooling system, what allowed to assess the influence of PCM application on the thermal conditions inside the room. Since only two extreme summer months were analysed thermal comfort was analysed only in terms of the risk of overheating and hours when indoor temperature exceeds the assumed cooling set point $\left(26^{\circ} \mathrm{C}\right)$ were taken into account.

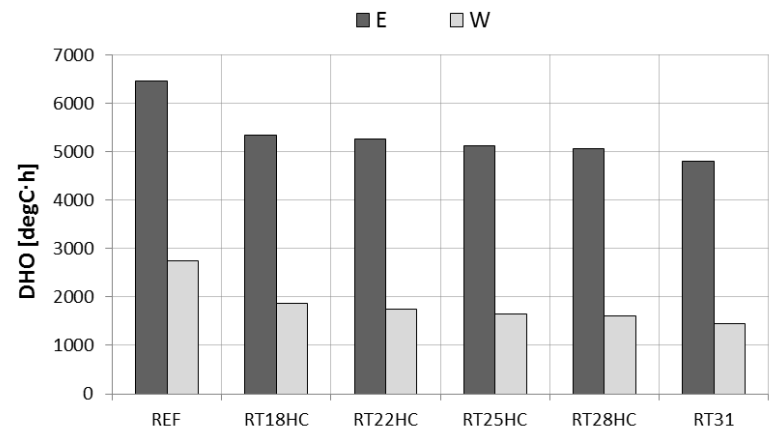

Figure 7. Degree-hours of overheating.

It can be observed that application of PCM in window cavity resulted in the reduction of the degree-hours of overheating as a result of the reduction of the indoor temperature. Furthermore, more detailed analysis of the temperature fluctuations inside the room revealed that PCM-window contributes to the reduction of the indoor temperature up to $4^{\circ} \mathrm{C}$ (Figure 8).

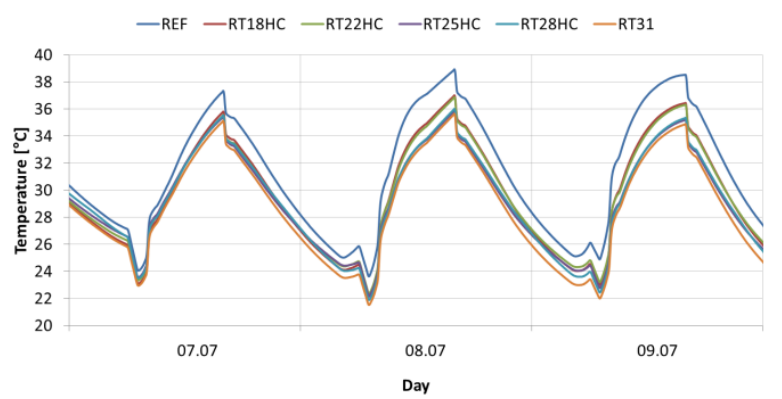

Figure 8. Internal temperature fluctuations for selected three days, for east oriented office.

\section{Visual comfort}

The last one aspect analysed using ESP-r was the influence of PCM application on the visual comfort. It was stated that two aspects of visual comfort should be considered: sky view and glare risk. Due to very low value of the visible transmittance of PCM in solid state it was assumed that for such conditions there will be no possibility to have view out through the window. On the other hand, PCM in the liquid state has visible transmittance quite similar to the reference "clear" window and do not disturb the view out. In order to quantitatively asses the visual comfort number of hours when sky view is not obscured were calculated.

Table 5. Assumptions for calculation of the number of the visual discomfort calculation

\begin{tabular}{|c|c|c|c|c|c|}
\hline $\begin{array}{l}\text { Orien } \\
\text { tation }\end{array}$ & Time & $\begin{array}{c}\text { Sky } \\
\text { conditions }\end{array}$ & $\begin{array}{l}\text { PCM } \\
\text { state } \\
\end{array}$ & $\begin{array}{c}\text { Glare } \\
\text { risk }\end{array}$ & $\begin{array}{l}\text { Sky } \\
\text { view }\end{array}$ \\
\hline \multirow{8}{*}{ East } & \multirow{4}{*}{$8-10$} & Clear & Solid & No & No \\
\hline & & Clear & Liquid & Yes & Yes \\
\hline & & Overcast & Solid & No & No \\
\hline & & Overcast & Liquid & No & Yes \\
\hline & \multirow{4}{*}{$10-16$} & Clear & Solid & No & No \\
\hline & & Clear & Liquid & No & Yes \\
\hline & & Overcast & Solid & No & No \\
\hline & & Overcast & Liquid & No & Yes \\
\hline \multirow{8}{*}{ West } & \multirow{4}{*}{$8-14$} & Clear & Solid & No & No \\
\hline & & Clear & Liquid & No & Yes \\
\hline & & Overcast & Solid & No & No \\
\hline & & Overcast & Liquid & No & Yes \\
\hline & \multirow{4}{*}{$14-16$} & Clear & Solid & No & No \\
\hline & & Clear & Liquid & Yes & Yes \\
\hline & & Overcast & Solid & No & No \\
\hline & & Overcast & Liquid & No & Yes \\
\hline
\end{tabular}

Moreover, calculation of the hours of visual comfort was complemented by the glare risk analysis. It was stated that during the sunny days, during the hours when sunbeams incidents directly on the window surface solid PCM will play a role of a shading device, protecting from the glare. For east façade such situation occurs at the morning hours and for west orientation at the afternoon. It means that during that time (when there is a glare risk) the fact that there is no sky view is positive effect of solid state PCM and that time is not calculated as time of discomfort. The sky conditions were assumed as clear and sunny if ratio between diffuse and direct solar radiation was less than 0.27 . Details of the sky view and glare risk assessment calculation were presented in Table 5. Values of the hours of visual discomfort were presented in Figure 9. 
a)
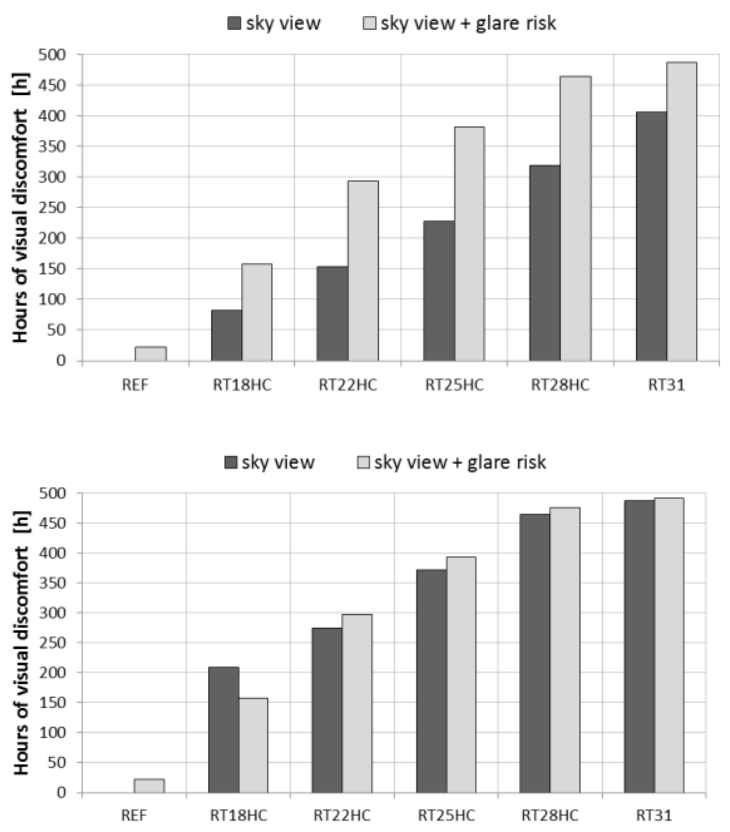

b)

Figure 9. Hours of visual discomfort for the windows directed: a) east, b) west.

Values of the visual discomfort referenced as "sky view" in Figure 9 reflects directly the number of hours then PCM was in solid state while the second one value named "sky view + glare effect" was recalculated adding hours when glare effect occurred or subtracting hours when solid state of paraffin contributed to the protection from the glare effect.

\section{Conclusions}

Today's pursuits approaching development in energy efficiency in building sector focuses mainly on the lowering heating energy demand. As a result, consideration of the cooling energy becomes more crucial, even in such cold climatic condition as characteristic for considered city of Lodz. It is expected that future buildings will be characterized by very good thermal insulation and so on very low heating demand, while problem of overheating seem to be left in the background. Considering those trends, PCM-windows should be suitable solution for newly designed, energy efficient buildings, contributing to the lowering the cooling demand during the extreme summer months.

The PCM application in the window cavity was comprehensively analysed taking into account both energy and comfort aspects. Based on the simulation results for all cases the amount of energy needed for cooling and lighting were compared. Based on the experimental analysis due to very low transmittance of PCM in solid state it was assumed that for the time when PCM is not liquid additional power of $90 \mathrm{~W}$ for lighting will be required. On the other hand, it was observed that due to limited solar energy transmission through solid PCM the energy demand for cooling was decreasing with the increase of PCM transition temperature.

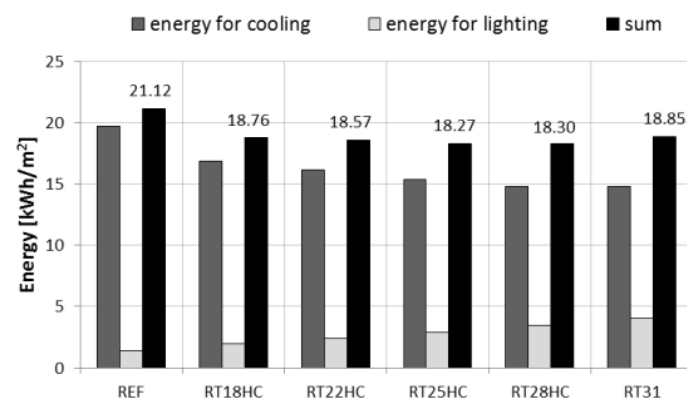

a)

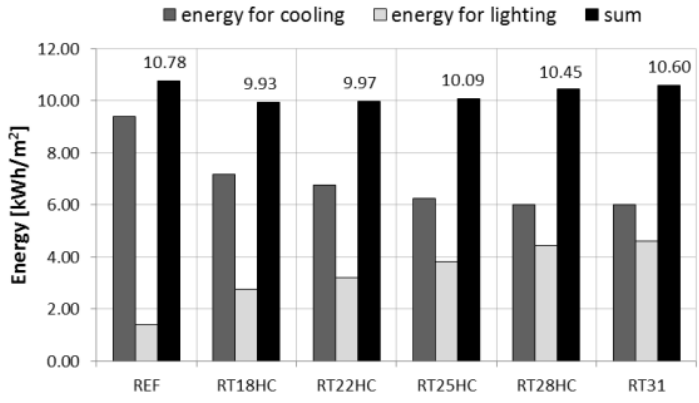

Figure 10. Energy demands for the case of windows directed: a) east, b) west.

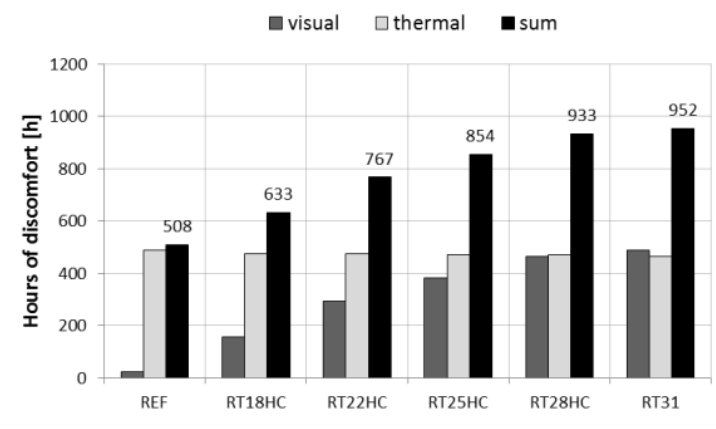

a)

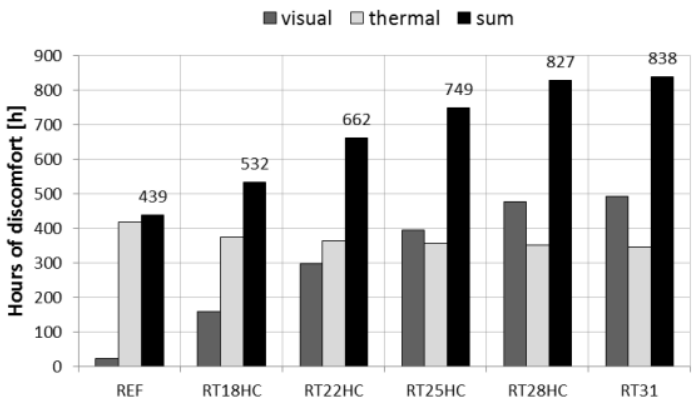

Figure 11. Hours of discomfort for the case of the windows directed: a) east, b) west.

Moreover, influence of the PCM application on the thermal and visual conditions inside the adjacent room was considered. It was assumed that standard window and window with liquid PCM can assure good sky view and visual comfort while PCM in solid state deteriorates those conditions. Nevertheless, lower light transmittance contributed to the limitation of the glare effect. Discomfort parameters were calculated by the number of hours when specific conditions were not met (Figure 11) while energy aspects in $\mathrm{kWh} / \mathrm{m}^{2}$ (Figure 10). 
Analysis of the energy effect of PCM application revealed that for east orientation the most effective performance was obtained for the paraffin RT25HC while for west orientation RT18HC. On the other hand, thermal and visual comfort analysis showed that the most suitable paraffin for both facades will be the one with the lowest considered melting temperature - RT18HC.

Finally, it was assumed that considered square $1 \mathrm{~m}^{2}$ window will be divided into 4 and 2 sections in case of east and west orientation respectively. Furthermore, according to the obtained results it was stated that central or lower part of the window will be filled with the paraffin selected accordingly to the comfort aspects and will assure the highest possible view out while the second half of the window surface will be dedicated to the overheating protection and filled with the paraffin selected due to energy demand results. Schematic view of the final window construction recommended for further experimental analysis was presented in Figure 12.

a)

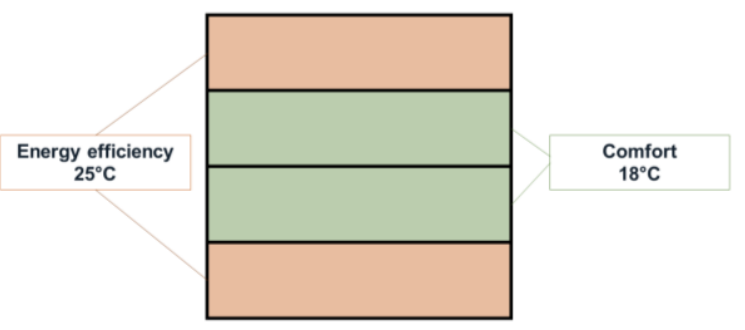

b)

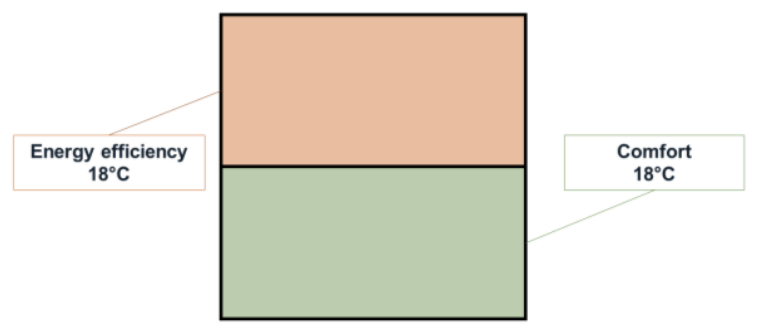

Figure 12. Schematic view of the construction and PCM temperatures for the windows directed: a) east, b) west.

\section{Acknowledgement}

This work was funded in a framework of ERANet-LAC 2nd Joint Call on Research and Innovation by NCBiR as part of the project entitled: Solar hybrid translucent component for thermal energy storage in buildings (acronym: SOLTREN)..

\section{References}

Goia, F., Perino, M., \& Serra, V. (2014). Experimental analysis of the energy performance of a full-scale PCM glazing prototype. Solar Energy, 100, 217233. https://doi.org/10.1016/J.SOLENER.2013.12.002

Goia, F., Zinzi, M., Carnielo, E., \& Serra, V. (2015). Spectral and angular solar properties of a PCMfilled double glazing unit. Energy and Buildings, 87 , 302-312. https://doi.org/10.1016/J.ENBUILD.2014.11.019

Heim, D., Knera, D., Krempski-Smejda, M., \&
Wieprzkowicz, A. (2018). Determination of total solar and visual radiation transmitted through triple glazing component with PCM layer IOP Conf. Ser.: Mater. Sci. Eng. 415(1):012041

Heim, D., Knera, D., \& Szczepanska-Rosiak, E. (2013). "Functionality of Active External Wall - Optimal Glazing / BIPV Ratio Taking Into Account Total Indoor Illuminance. Proceedings of 13th Conference of International Building Performance Simulation Association, 2765-2773. http://www.ibpsa.org/proceedings/BS2015/p2638. pdf

Ismail, K. A. R., \& Henríquez, J. R. (1997). PCM glazing systems. International Journal of Energy Research, 21(13),

1241-1255. https://doi.org/10.1002/(SICI)1099114X(19971025)21:13<1241::AIDER321>3.0.CO;2-T

Li, D., Li, Z., Zheng, Y., Liu, C., Hussein, A. K., \& Liu, X. (2016). Thermal performance of a PCM-filled double-glazing unit with different thermophysical parameters of PCM. Solar Energy, 133, 207-220. https://doi.org/10.1016/J.SOLENER.2016.03.039

Li, D., Ma, T., Liu, C., Zheng, Y., Wang, Z., \& Liu, X. (2016). Thermal performance of a PCM-filled double glazing unit with different optical properties of phase change material. Energy and Buildings, 119 , 143-152. https://doi.org/10.1016/J.ENBUILD.2016.03.036

Liu, C., Wu, Y., Li, D., Zhou, Y., Wang, Z., \& Liu, X. (2017). Effect of PCM thickness and melting temperature on thermal performance of double glazing units. Journal of Building Engineering, 11, 87-95. https://doi.org/10.1016/J.JOBE.2017.04.005

Liu, C., Wu, Y., Zhu, Y., Li, D., \& Ma, L. (2018). Experimental investigation of optical and thermal performance of a PCM-glazed unit for building applications. Energy and Buildings, 158, 794-800. https://doi.org/10.1016/J.ENBUILD.2017.10.069

Silva, T., Vicente, R., \& Rodrigues, F. (2016). Literature review on the use of phase change materials in glazing and shading solutions. Renewable and Sustainable Energy Reviews, 53, 515-535. https://doi.org/10.1016/J.RSER.2015.07.201

S Strachan P. (1990) 'Addition of Blind/Shutter Control to Transparent Multilayer Constructions and Other Improvements to the Solar Routines of ESPsim', ESRU Technical Report, University of Strathclyde, Glasgow.

Zhong, K., Li, S., Sun, G., Li, S., \& Zhang, X. (2015). Simulation study on dynamic heat transfer performance of PCM-filled glass window with different thermophysical parameters of phase change material. Energy and Buildings, 106, 87-95. https://doi.org/10.1016/J.ENBUILD.2015.05.014 